Supplementary information

\title{
Gelation of a Pentapeptide in Alcohols
}

Tingyuan Tan, ${ }^{a, b}$ Zhen Guo, ${ }^{a, b}$ Yujiao Wang, ${ }^{a, b}$ Yuwen Ji, ${ }^{a, b}$ Jun Hu, ${ }^{a, c}$ and Yi Zhang a, ${ }^{*}$

${ }^{a}$ Key Laboratory of Interfacial Physics and Technology, Shanghai Institute of Applied Physics,

Chinese Academy of Sciences, Shanghai, China;

${ }^{\mathrm{b}}$ University of Chinese Academy of Sciences, Beijing, China;

c Zhangjiang Lab, Shanghai Advanced Research Institute, Chinese Academy of Sciences, Shanghai, China;

*Corresponding author. Email: zhangyi@sinap.ac.cn

Table of contents:

1. Figure S1. SEM images of self-assembled EAF-5 gels in different alcohols

2. Figure S2. SEM images of self-assembled EAF-5 fibers in different alcohols

3. Figure S3. The height of the single EAF-5 fiber formed in the different alcohols.

4. Figure S4. ATR-FTIR spectra of EAF-5 in different alcohols. 
5. Figure S5. ATR-FTIR spectra of EAF-5 in different alcohols.
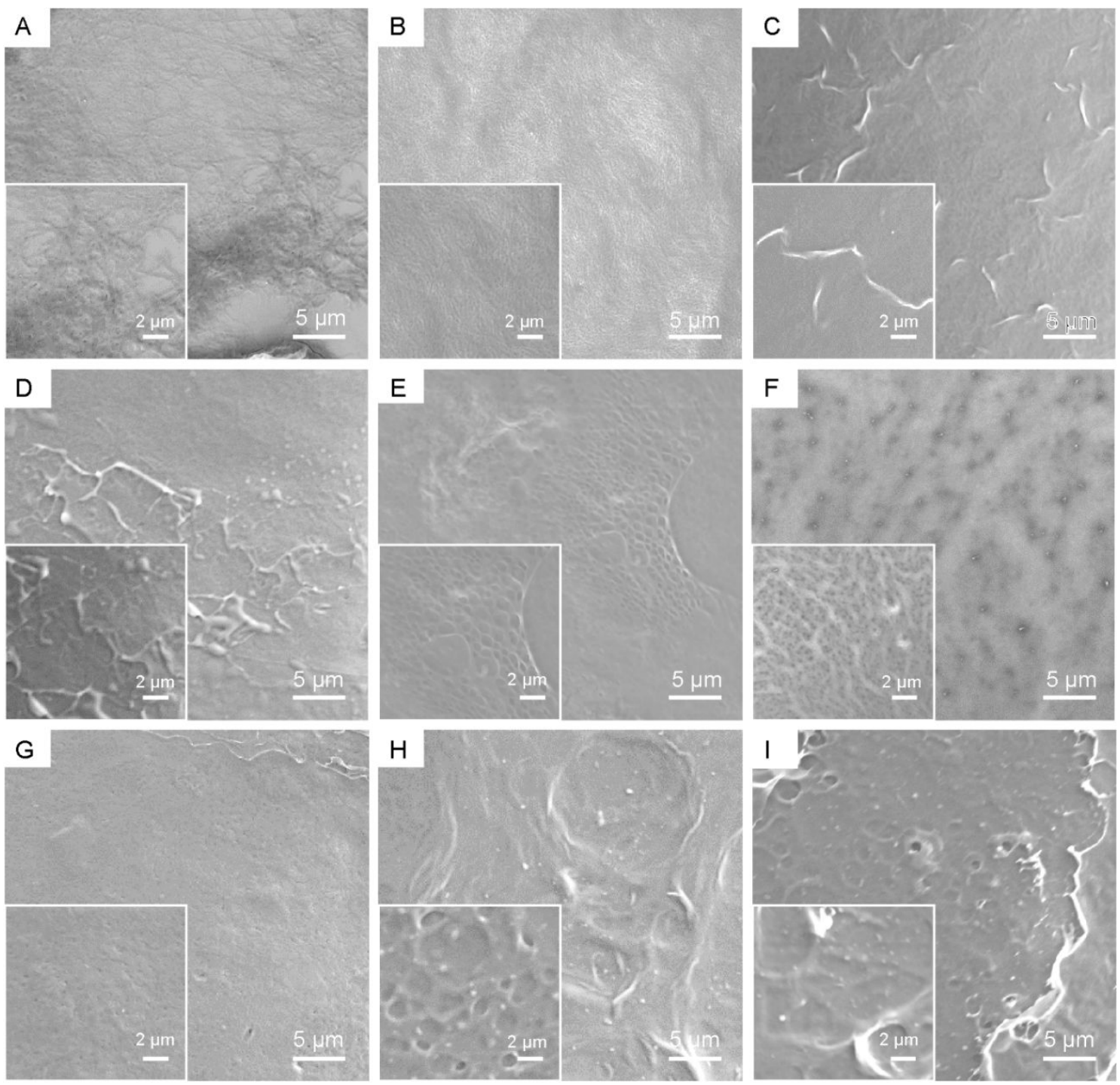

Figure S1. SEM images of self-assembled EAF-5 gels in different alcohols involving (A) ethanol, (B) n-propanol,

(C) iso-propanol, (D) n-butanol, (E) iso-butanol, (F) sec-butanol, (G) tert-butanol, (H) n-pentanol and (I) nhexanol. SEM measurements were performed by a field emission SEM instrument (LEO 1530VP). The imaging of samples was conducted at a $5 \mathrm{k}$ voltage. SEM samples were prepared by dropping $10 \mu \mathrm{l}$ peptide gels (12.5 
$\mathrm{mg} \cdot \mathrm{ml}^{-1}$ ) onto $1 \mathrm{~cm} \times 1 \mathrm{~cm}$ silicon substrates and was allowed to absorb for $10 \mathrm{~min}$, followed by freeze-drying for $12 \mathrm{~h}$. A palladium film was sprayed on all the freeze-dried samples to increase the conductivity for clear observation and imaging.
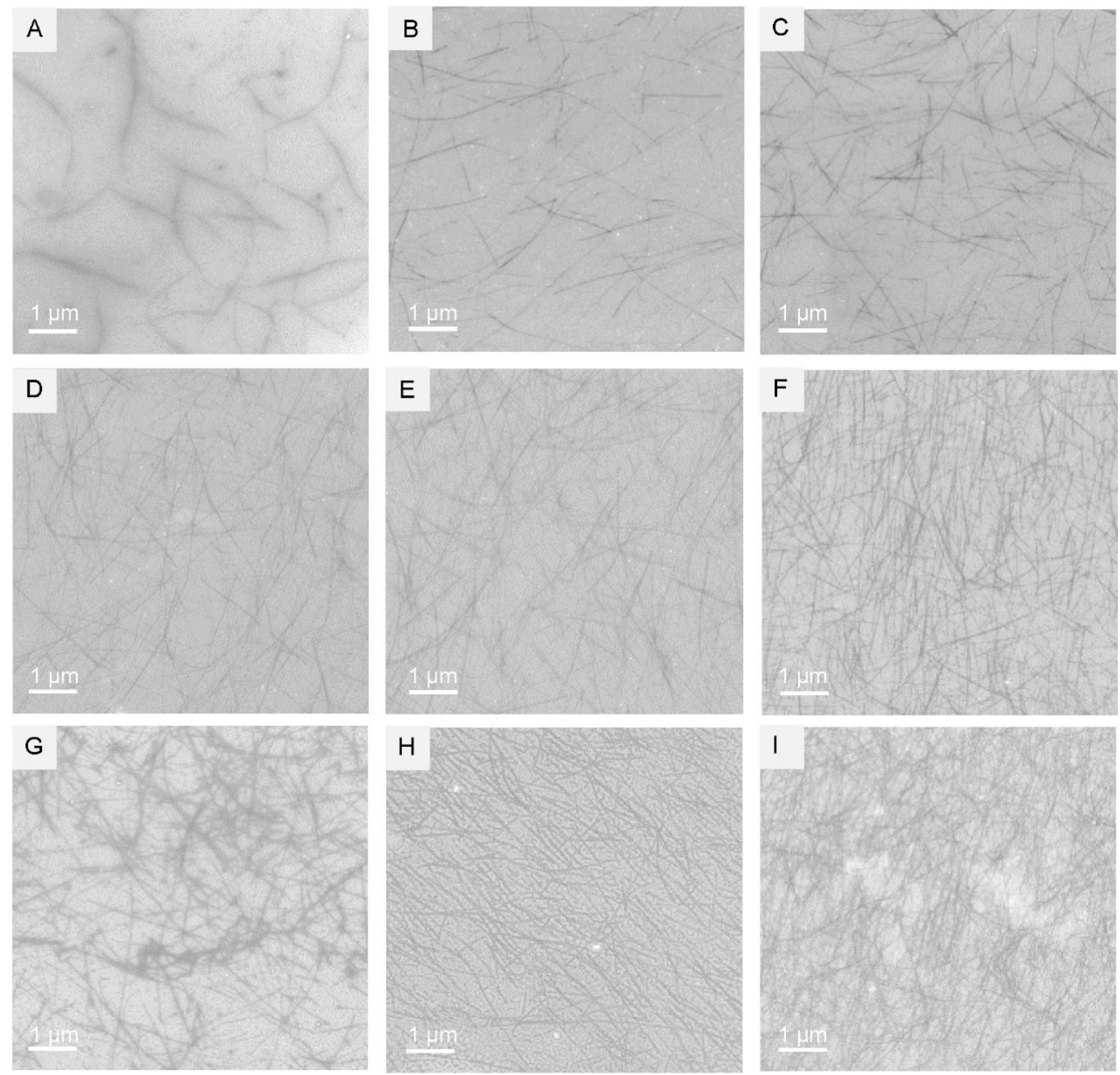

Figure S2. SEM images of self-assembled EAF fibers in different alcohols involving (A) ethanol, (B) n-propanol,

(C) iso-propanol, (D) n-butanol, (E) iso-butanol, (F) sec-butanol, (G) tert-butanol, (H) n-pentanol and (I) n- 
hexanol. SEM measurements were performed by a field emission SEM instrument (LEO 1530VP). The imaging of samples was conducted at a $5 \mathrm{k}$ voltage. SEM samples were prepared by firstly dispersed the EAF- 5 peptide to a concentration of $0.25 \mathrm{mg} \cdot \mathrm{ml}^{-1}$. Then, a drop of the peptide solution was dropped onto $1 \mathrm{~cm} \times 1 \mathrm{~cm}$ silicon substrates and was allowed to absorb for $10 \mathrm{~min}$. The excess liquid was removed by the filter papers, followed by drying for $5 \mathrm{~h}$ at $60^{\circ} \mathrm{C}$. Palladium spray was performed to increase the conductivity of all the dried samples for clear observation and imaging.

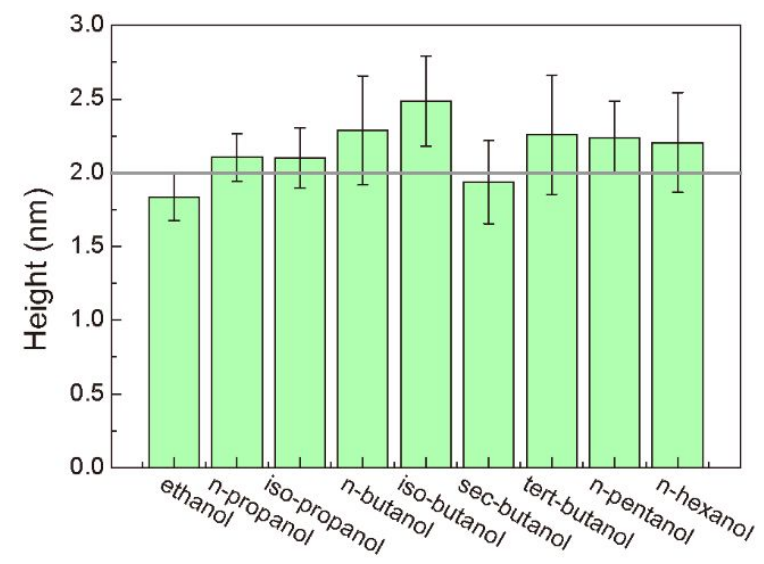

Figure S3. The height of the single fiber formed in the different alcohols as measured by AFM.

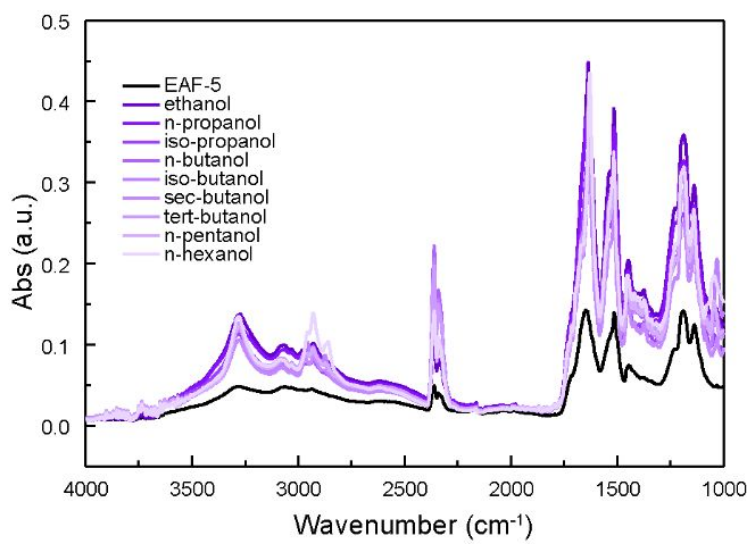


Figure S4. ATR-FTIR spectra of EAF-5 in different alcohols at the wavenumber from $4000 \mathrm{~cm}^{-1}$ to $1000 \mathrm{~cm}^{-1}$.

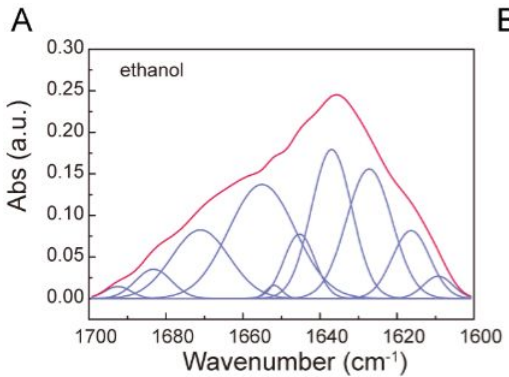

$\mathrm{D}$

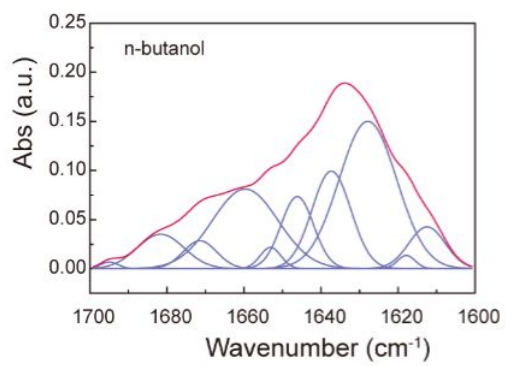

G

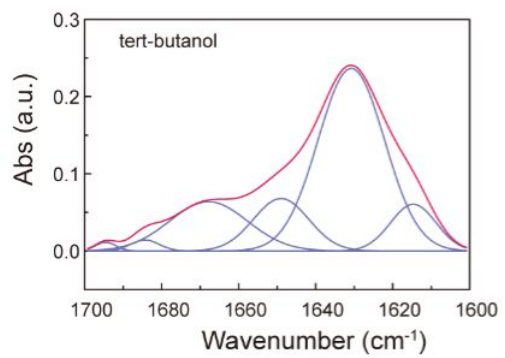

B

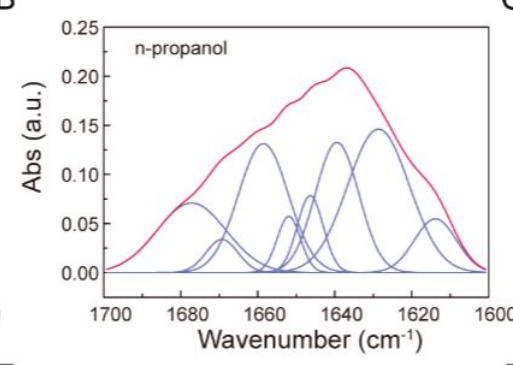

$\mathrm{E}$

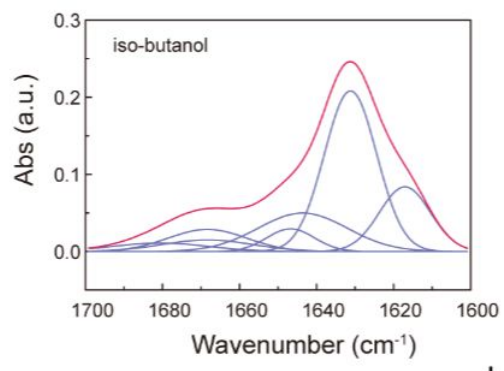

$\mathrm{H}$

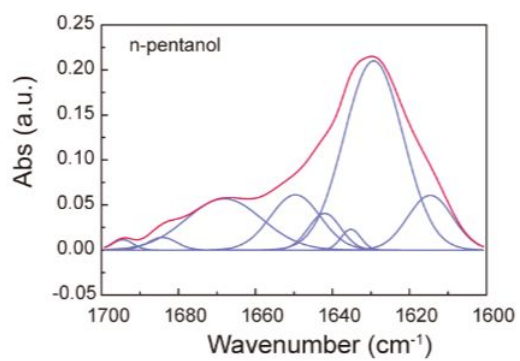

$\mathrm{F}$
C
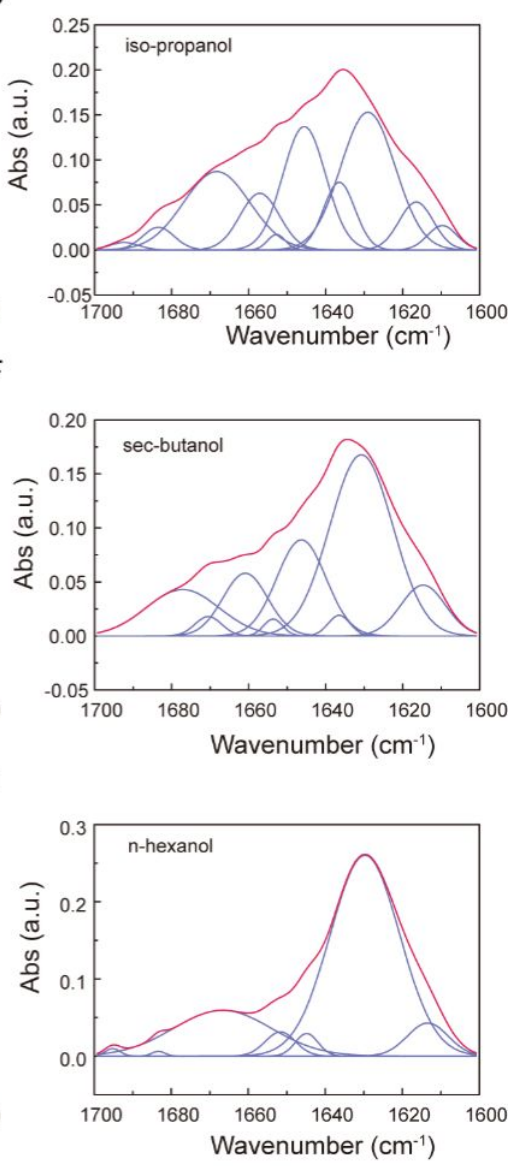

Figure S5. FTIR spectra showing the amide I bands of EAF-5 in different alcohols including (A) ethanol, (B) npropanol, (C) iso-propanol, (D) n-butanol, (E) iso-butanol, (F) sec-butanol, (G) tert-butanol, (H) n-pentanol and (I) n-hexanol. Bands between 1690-1678 $\mathrm{cm}^{-1}$ were assigned to antiparallel $\beta$-sheet, $1676-1663 \mathrm{~cm}^{-1}$ to $\beta$-turns, $1662-1645 \mathrm{~cm}^{-1}$ to $\alpha$-helices, $1644-1635 \mathrm{~cm}^{-1}$ to random coil, and $1634-1610 \mathrm{~cm}^{-1}$ to $\beta$-sheet, respectively. ${ }^{1}$

\section{REFERENCES}


1. Elfrink, K.; Ollesch, J.; Stöhr, J.; Willbold, D.; Riesner, D.; Gerwert, K., Structural Changes of Membrane-Anchored Native PrPC ${ }^{C}$ Proc. Natl. Acad. Sci. U.S.A. 2008, 105, 10815-10819. 